\title{
Integration of minorities in the EU states through public policies
}

\author{
Andrei Ghimisi ${ }^{1}$ \\ ${ }^{1}$ National University of Political Studies and Public Administration \\ E-mail: ghimisi4567@gmail.com
}

\begin{abstract}
The paper "Integration of minorities in the EU states through public policies" wishes to present the problem of the integration of minorities within the EU states and to present how these problems are tackled through public policies. There are presented types of policies and how they affect direct and indirect the people that are the subject of these public policies and also what are the main areas in which visible changes have been made through the years. Another important subject that is presented, the problem of migration and refugees, is connected with the topic of integration, as being inter-dependent. Key findings are presented that show the main areas of focus, the main targeted people and concerns regarding the near future and how to improve the process of integration within the EU states
\end{abstract}

Keywords: minorities, public policies,

\section{1,Introduction}

The integration of minorities has been a much-disputed subject through time and suffering many changes because of its complexity. Because of this, the researches on the topic needed to be expanded in order to fully grasp the meaning of the term "integration" and in order to create public policies that go through all the steps that are necessary for this process to be a success.

International migration evolved as an important component in the process of liberalization and economic expansion, which took place in Western Europe after the Second World War. Whether as migrant receivers (north Western Europe) or as migrant-senders (southern Europe), all states became connected into an expanding migration 'systern', which soon extended beyond the region, incorporating former colonies and other states to the south and to the east.

As presented earlier, the term "integration" has a very vast understanding and because of this it makes the process for it to be defined in a precise way even harder. For a proper integration of minorities, this integration must be made at every level and in every sector of society. Its range ca vary from a long list of social actors: political decision-makers, public officials, employers, fellow-workers, trade union officials, neighbours and so on. Members of minorities also play a crucial role in this process.

Seeking to accommodate minority claims implies searching for a balance between separation and unity, cohesion and respect for diversity. If one prefers solely unity, the risk is assimilation and the disappearance of a minority as a distinct group; if one chooses exclusively diversity, then the result can be the cultural 'ghettoization' of a minority group with consequent separation and marginalisation from society. 
In order to understand this process we must go deeper and study it from not only a single social science, but almost all. Economics, law history, political science, sociology, anthropology, geography, urban studies, demography and psychology all have a part to play. As hard as it is to put a definition on integration, it can be assumed that the terms is generally attributed to be a universal, singular, stagesequential and regular paces process which all members of minorities are exposed. It is within these presumed universal stages that minorities are often judged in public discourse to have either 'successfully' or 'unsuccessfully' integrated.

\section{Public policies: types and areas of focus}

In Europe, as the case study, a deteriorated political, economical and social situation is generally unfavourable towards the encouragement and promotion of policies regarding diversity through for instance, affirmative exemptions or actions from general rules. Indeed, in some countries that have celebrated multiculturalism, such as the Netherlands, this model is experiences a reverse process even if there are more and more evidences that multiculturalism is still a current valid policy option.

Several Government programmes, most notably those of Hungary, the Czech Republic, Bulgaria and Romania - reflect a comprehensive approach in regards to minority protection, clearly stating an intent to address discrimination as well as to promote minority identity. In Latvia and Estonia, where the principal target is Russian-speaking populations, Government programmes do not purport to guarantee comprehensive minority protection and instead promote societal integration through acquisition of proficiency in the State language.

It is important to perceive minorities as active participants in the individual collective process of integration. One of the first steps in the process of integration operates through the consolidation of relationships with family and extended kin groups, then sub-groups and wider ethnic groups, then neighbourhood and cities, and finally into what is called a national society as a whole. All of this so called "nested processes" should and must be recognized in policy terms, since there are so many different domains of policies that can impact on each level of integration in this process.

Although, for example, the protection of Roma culture is a priority for many Roma civil society organisations, this dimension of minority policy is not fully elaborated by any of the Government programmes, though integration is often identified as an objective. In fact, the inclusion of "socialisation" elements in many programmes (Lithuania, Hungary, Poland, and Slovenia) suggests that Roma culture is still identified with deviance, poverty, and other negative characteristics, and is viewed as being at odds with majority society.

There are four dimensions regarding the process of integration that can be differentiated: legal or structural integration, which means the acquisition of rights and the access to membership, statuses and positions in the cores institutions of the society (training system, education system, labour market, citizenship, housing, trade unions and more). Another dimension in this process is the Cultural integration, which is a precondition of participation and refers to the process of cognitive, behavioural, cultural and attitudinal change in people. This change is mostly focused and concerned on minority groups, but is also an interactive, mutual process that changes the dominant/majority society as well. Cultural integration is a rather heterogeneous area relating to, cultural competences, popular culture, values and beliefs, and everyday practices.

Another important factor that can share some light in the process of the integration of minorities in the private sphere is presented in the people's private relationships and group memberships (friendships, social intercourse, marriages, and voluntary associations). All of these refer to the third dimension, which is social integration. The membership within a new society is manifested in the sense of identification and belonging, particular in the form of ethnic and/or national identification. This leads to the identification of the fourth dimension that is identification integration.

As a result, the meaning of integration policies can be explained as an access to position and statuses, an acquisition of rights, a building of social relations, a change in individual behaviour and a formation of feeling of identification and belonging by minorities towards the community in which they live. 
Speaking in general terms, integration policies can be split into two types: targeted policies only aimed at specific types of persons that are disadvantaged and general policies aiming to improve the position of all people who are discriminated or marginalized or are at risk of becoming so. This can also be explained as direct and indirect integration policies. Some examples regarding indirect and direct policies could be those in which long-term unemployed have access to job schemes or retraining programmes, or, on a different front, urban renewal schemes, improving house quality, infrastructure and the like, in principle equally benefiting minority and majority groups or natives and immigrants ${ }^{1}$. Good examples regarding direct integration policies are those that assist minorities who lack the basic attributes needed to participate on the labour market, such as language courses or training courses to bring immigrants skill up to the necessary level.

A secure residence status for immigrants is a necessary prerequisite for their integration. Without security, a person cannot feel part of the receiving society and has little incentive to take steps to become part of it. Public authorities too have little to no incentive to include immigrants with uncertain status in social welfare programmes, and they may have limited access to social housing and healthcare. Temporary status also reduces employability, and restricts immigrants to temporary, low skilled work. It is important for residence permits to be issued in a relatively short time.

Governmental minority protection programmes are moreover policy documents, rather than legislative acts. As such, in most of the cases the bodies primarily responsible for fully elaborating them and overseeing their implementation are specialised departments within Government ministries. However, these bodies seldom are authorised to do more than compile reports using information voluntarily supplied by participating ministries, and lack the mandate to coordinate the activities of other Government institutions efficiently and effective

Other measures that were adopted by some governments regarding integration policies consist in the form of 'introduction programs' for the early phase of immigrants stay ${ }^{2}$. The introduction programmes consists in general of three main components: civic orientation, language tuition and professional labour market training. In particular, in those countries in which immigrants and refugees that are newly arrived do not have yet the knowledge of the native language through colonial or other ties, the language teaching programmes constitutes the centrepiece of introduction by the efforts of the respective state governments.

Beside language, 'social orientation' is another important factor that is presented in the introduction courses and also the importance of giving immigrants the knowledge of the functioning and the values of the host city is another element which is discussed. In these courses, the people can find the fundamental elements regarding the constitution, such as the respect for democracy and human rights, and the functioning of the political system including opportunities for participation in civil and political society. Gender equality and children's rights are other crucial components of many orientation programs. Regarding this subject, Joppke and others have interpreted integration programmes as those encouraging minorities to learn the official language or promoting citizenship ceremonies and others, citizenship education, or those labelled ' society orientation classes' as a 'retreat from multiculturalism'3.

Other types of integration policies are the ones that extend the right to vote to non-citizens in order to increate their political participation and sense of belonging to a society. Also, it can help the established institutions to know what are the minorities problem by hearing and understanding their claims. In addition to this, policies are also conceivable whereby minorities are offered facilities for retaining some of their core aspects in their culture, such as religion or are even encouraged to do so.

Broad public support is generally considered to be necessary for the implementation of any largescale political programme, but the rapid pace of the accession process has meant that building public support for governmental policy often has been given short shrift in the wake of the broader accession

\footnotetext{
${ }^{1}$ EU, A Common Agenda for Integration, 2005, CBP 1

${ }^{2}$ EU, Handbook on Integration Policies, 19

3 Joppke Christian "Towards Assimilation and Citizenship", 2003.
} 
imperative. Measures that need to be adopted to comply with economic requirements can be more easily justified by political leaders in terms of the economic benefits that Union membership is widely expected to produce. However, the case for the advantages and benefits to society as a whole of improving the situation for minorities has not been so persuasively made.

There are some problems regarding these types of direct integration policies, especially those that are brought under the general heading of positive action. Quota may be laid down in law or be institutionalized practice by which people that are belonging to disadvantaged ethic groups are receiving some kind of preference when applying for places in educational system or jobs.

These types of policies can be active, for example, when employers face the obligation to give preference to members of such specified population categories in working places, or they can be passive, when they are under an obligation, for instance, to report the relative numbers of such persons in their work force. Somewhere between passive and active policies are those whereby government institutions prefer to offer projects to employers with a certain minimum number of disadvantaged workers among the employees.

As presented, integration policies touch upon very different aspects of the majority-minority relationship, not only the cultural, legal, and social dimension, but also the sense of belonging and citizenship, the identification aspects that come along with it, complementary identities, they all represent a crucial aspect of the integration process.

\section{Migration: a challenge for Europe}

Integration is an open-ended, long-term process that requires a range of police actions that are taken at different stages and directed at a combination of targeted groups. Many of these policies address the impact and the consequences of migration and, as such, are targeted at refugees and migrants at various stages of the settlement process. Other policies are shaped in order to address racial, religious or ethnic differences, and thus focus on the management of diversity, regardless of its relation to migratory environments.

Regarding the aspect of migration management, a number of states offer, or plan to provide, special programmes for recognised refugees or newcomers holding residence permits. This comes as a reflection of the European Commission suggestion to offer "settlement packages", 4 In terms of naturalisation and its process. Candidates are sometimes required to take classes on citizenship and pass language tests, for example in Germany, Netherlands and Austria, which are thought to serve as integration helps for prospective citizens. Even though all the measures can seem to be potentially valuable, they can also shape barrier to participation and tend to be reserved for certain groups of migrants( for example if training expenses are involved. For spouse of primary migrants, 'guest workers', asylum seekers and irregular migrants, the restriction of socio-economic opportunities and rights at the begging of their stay can have a serious adverse impact on their integration trajectory.

Because of this, it is important that the measures are not only developed for all types of migrants, but are also accompanied by policies that want to minimise any disadvantages that may be caused bu a restricted legal status upon arrival.

Policies that are lead from initial arrival measures and address the long-term settlement of migrants are required to focus on the promotion of equal opportunities in relation to the native population. Such measures overlap with general policies that are aimed at managing diversity with a view to ensuring social cohesion ${ }^{5}$. Where the policy management of diversion intersects with that of the diversity, targeted groups are identified according to their migration experience on the one hand, and their ethnic, religious and racial background on the other. While migrants are often seen as ethnic or racial minorities, there is no necessary correlation between these two-targeted groups, which can also include large numbers of

\footnotetext{
${ }^{4} \operatorname{COM}(2000) 757$ final, Communication from the Commission to the Council and the European Parliament, (Brussels, 22.11.2000), 20.

${ }^{5}$ Mary Coussey, Framework of Integration Policies, Council of Europe (Strasbourg 2000)
} 
white migrants from Western countries who face no particular problem of integration. There can also be some racial and ethnic minorities in the EU, who have no recent migratory background, and yet encounter the same obstacles to full inclusion. Finally, there are some white migrants, for example from Eastern Europe, who suffer from exclusion, which may be related to their distinct ethnic, cultural or religious identification. As integration policies are formed, they need to take into account the main factor that is affecting the integration of migrants and that is the prevalence of racism. An example is presented in the case of asylum seekers where they are often racially designed and stereotyped in public discourse, even though many are in fact white.

While some EU member states now aim to capture second-generation migrants into their statistics by adding the category of nationality at birth, it is also perceived that this is only a temporary stopgap before the introduction of detailed ethnic minorities' categories. It is also important for the people that shape these policies to recognise that the adoption of policies targeted at specific ethnic groups as well as ethnic monitoring does not constitute a division of human beings into fixed groups, but is moreover a vital tool for delivering successful outcomes and for identifying the needs of the targeted people.

The aspect of the integration of migrants in the labour market has been and, in the light of the recent events, still is, one of the main priorities in the framework of the European Union. Because of this, the European Commission recommends greater resort to a combined strategy with the help of the European Social Inclusion Process in order to eliminate the barriers of integration. This initiative is created in order to support innovative good practices that can prevent unemployment and fight labour marked discrimination of immigrants, including xenophobia and racism.

In regards to the problem of migration and its continuous increase to an unpreceded level in the last years we must understand the meaning and what does it truly mean for the process of integration. The aspect of social cohesion is raised when we talk about migration and it reveals an unequivocal urgency for many if not most of the countries that consider themselves to be reasonably homogenous and cohesive. The result consists in the process of integration of minorities to be adopted by most countries in order to retain an adequate level of social prosperity and cohesion.

Because of the unfavourable situation of immigrants in respect to unemployment and wages compared with native workers in many Member States, their integration is identified as one of the main and top priorities by the European governments. Enhanced integration could lead to a massive reduction in the unemployment gap between non-EU and EU nationals that exists in the Member states.

Integration is perceived now, and ever since the Amsterdam Treaty, as a process that can be achieved by appropriate common, proactive and comprehensive policies. In this regard, EU has moved forward towards establishing a legal framework for managing migration, calling for " more efficient management of migration flows at all their stages" and providing for a common migration policy that included legal migration and integration"6.

The Communication on Immigration, Integration and Employment of the Thessaloniki Summit of 3 June 2003 was perceived as a basis for developing EU integration polices. One of the most important message for this Communication was the in creation of immigration flows that are necessary in the EU. With this in mind, the second message that was outlined was that a better integration if immigrants should be achieved as a condition of future immigration. Not only this, but another important topic that was discussed is that more coherent framework of integration policies must be created at the EU level.

The European Commission underlines the necessity for minorities and migrants to be able to access the labour marked and integrate with an equal status to the native workers. In 2006, the problem of migration was considered to be by the European Council Presidency's Conclusions as "'one of the major priorities for the EU at the start of the $21^{\text {st }}$ century".

The problem of migration and how it can be properly dealt with was a topic to be discussed also over the following years. 'Strengthening the Global Approach to Migration, 'A Common Immigration Policy for Europe, Pact on Immigration and Asylum are also other important moments that helped shaped the

\footnotetext{
${ }^{6}$ European Council (TAMPERE), “Tampere European Council, 15 and 16 October 1999, Presidency Conclusions", 1999
} 
public policies that are directed towards migration and the integration of minorities in the EU states. The main focusses in the examples above are focused mainly on legal immigration and integration, border controls. The control of illegal immigration, migration and development, and the finalisation of a common European asylum system. In these pacts, the need to treat migrants fairly and promote their integration into society with an emphasis on measures promoting language acquisition and access to employment are emphasized. It also invites the Members States to combat any forms of discrimination to which migrates may be exposed.

The integration of refugees is another important topic, which the EU has been covering especially in the last years. Within its specialized body, the European Council on Refugees and Exiles several steps have been made in order to help improve the situation of refugees. Firstly, there are some legal steps, such as facilitating the application and acquisition of citizenship and easing the restriction on family reunification. After this step, some practical actions are needed, such as free language and orientation programmes, including during the reception phase, and policies encouraging and promoting civic, cultural and socio-economical participation.

\section{Conclusion}

In conclusion, there are several factors that are important to see when we are to discuss the problem of integration. Because of the fact that the term is very complex in its understanding, it makes it difficult to put a precise definition. Through the years, the EU has made more and more steps towards the implementation of a healthy and balanced environment in which the people to feel welcomed and can easily integrate in the respective society. There are several challenges that need to be fixed and dealt with properly in order for this environment to nourish. Changes need to be made in all sectors, especially in the educational and labour market system, in order to facilitate the integration of minorities in the EU states.

The problem of migration is another topic that concerns the EU and tis member states. Because of the huge waves of refugees that came across Europe in the last years, the system and its structure was not prepared and presented some flaws within its mechanism. In order to fix them, several steps were made by the European Union Council in order to eliminate, as much as it could, the gap socioeconomical gap between the migrants, refugees and the native people of the respective states.

To sum up, the problem of migration, refugees and minorities are in strong connection one and other. Changes within the system of all member states are needed in order to facilitate their integration in the states. From language courses to training courses in order to initiate in the labour market, all represent key steps towards the integration of people from different states, even if they are of different religion or other consideration, inside the European Union system within the respective state. All people should have equal chances and compensation when applying for a job and must not be judged by the colour of their skin, religion or any other different considerations.

\section{References}

[1] EU, A Common Agenda for Integration, 2005,

[2] EU, Handbook on Integration Policies.

[3] Joppke C., Morawska, E. (2003): Towards Assimilation and Citizenship, Macmillan

[4] Communication from the Commission to the Council and the European Parliament, (Brussels, 22.11.2000), 20.

[5] Coussey, M.(2000): Framework of Integration Policies, Council of Europe (Strasbourg)

[6] European Council (TAMPERE), (1999) Tampere European Council, 15 and 16 October 1999, Presidency Conclusions

This paper was elaborated within the Human Capital Operational Program 2014-2020, co-financed by the European Social Fund, under the projectPOCU/380/6/13/124708 no. 37141/23.05.2019, with the title "Researcher-Entrepreneur on Labour Market in the Fields of Intelligent Specialization (CERTANTREP)", coordinated by the National University of Political Studies and Public Administration. 